\title{
Y chromosome copy number variation and its effects on fertility and other health factors: a review
}

\author{
Marc J. Rogers \\ Department of Urology, Medical University of South Carolina, Charleston, SC, USA \\ Correspondence to: Marc J. Rogers, MD. Department of Urology, Medical University of South Carolina, 96 Jonathan Lucas St., CSB 620, Charleston, \\ SC 29403, USA. Email: rogermar@musc.edu.
}

\begin{abstract}
The Y chromosome is essential for testis development and spermatogenesis. It is a chromosome with the lowest gene density owing to its medium size but paucity of coding genes. The Y chromosome is unique in that the majority of its structure is highly repetitive sequences, with the majority of these limited genes occurring in 9 amplionic sequences throughout the chromosome. The repetitive nature has its benefits as it can be protective against gene loss over many generations, but it can also predispose the $\mathrm{Y}$ chromosome to having wide variations of the number of gene copies present in these repeated sequences. This is known as copy number variation. Copy number variation is not unique to the $\mathrm{Y}$ chromosome but copy number variation is a well-known cause of male infertility and having effects on spermatogenesis. This is most commonly seen as deletions of the AZF sequences on the Y chromosome. However, there are other implications for copy number variation beyond just the AZF deletions that can affect spermatogenesis and potentially have other health implications. Copy number variations of TSPY1, DAZ, CDY1, RBMY1, the DYZ1 array, along with minor deletions of $\mathrm{gr} / \mathrm{gr}, \mathrm{b} 1 / \mathrm{b} 3$, and b2/b3 have all be implicated in affecting spermatogenesis. UTY copy number variations have been implicated in risk for cardiovascular disease, and other deletions within gr/gr and the AZF sequences have been implicated in cancer and neuropsychiatric diseases. This review sets out to describe the $\mathrm{Y}$ chromosome and unique susceptibility to copy number variation and then to examine how this growing body of research impacts spermatogenesis and other health factors.
\end{abstract}

Keywords: Azoospermia; copy number variation; male infertility; spermatogenesis; Y chromosome

Submitted Nov 16, 2019. Accepted for publication Apr 06, 2020.

doi: $10.21037 /$ tau. 2020.04 .06

View this article at: http://dx.doi.org/10.21037/tau.2020.04.06

\section{Introduction}

Infertility is estimated to affect $10-15 \%$ of couples with male factor being the solitary cause in about $20 \%$ of those cases and playing a role in another $40 \%$ of cases (1-4). A semen analysis is the workhorse of a male factor workup and when a result returns with a concentration of $<5$ million sperm $/ \mathrm{mL}$ it is recommended that the patient undergo genetic testing (5). The two most common genetic tests are a karyotype and a $\mathrm{Y}$ chromosome microdeletion (YCMD) analysis $(5,6)$. It is estimated that karyotypic abnormalities will be found in 3-5\% of oligospermic men and up to $19 \%$ of men with non-obstructive azoospermia (NOA) $(7,8)$. YCMD are found in 2-5\% of severely oligospermic men and $5-10 \%$ of men with NOA (9-11).

Copy number variants (CNV) are well known in the human genome as they allow for phenotypic diversity (12). $\mathrm{CNV}$ affect more nucleotides in the human genome than SNPs and can arise via several mechanisms including; non allelic homologous recombination, non-homologous end joining, and retroelement insertions $(13,14)$. However, $\mathrm{CNV}$ can also lead to negative consequences and have been implicated in intellectual disability (15), epilepsy (16), cancer (17), and other disease processes. For reasons we will discuss further, the $\mathrm{Y}$ chromosome is particularly susceptible to $\mathrm{CNV}$ which can lead to fertility issues. The most wellknown CNV on the $\mathrm{Y}$ chromosome are the total AZF 
deletions, but also includes AZFc partial deletions, such as $g r / g r$ gene alterations, and the TSPY gene array. The AZF deletions will be discussed in detail in another article in this journal and will only be touched on briefly here. And while most studies of CNVs have revolved around fertility, there is some growing evidence that they could lead to other health issues, such as cancer (18).

\section{The Y chromosome}

The $\mathrm{Y}$ chromosome is acrocentric, meaning it contains a shorter Yp and longer Yq arm, with a total of around 60 million-base $(\mathrm{Mb})$ pairs, making it one of the smallest chromosomes in the human genome. It is one of the most unique and important chromosomes, as amongst other genes, as it contains the $S R Y$ gene region that provides the genetic data for embryonic sex determination. Yet, it is also the only chromosome that can be missing entirely without lethal consequences (19). Due to an evolutionary effect known as gene decay, where unused genes are slowly removed from the genome, the $\mathrm{Y}$ chromosome now contains 54 protein coding genes compared to the $\mathrm{X}$ chromosome that contains approximately 700 protein coding genes. The $\mathrm{Y}$ chromosome is generally divided into two domains, the pseudoautosomal regions (PAR1 and PAR2) and an area known as male-specific Y region (MSY) $(9,20)$. The PAR regions contain genes that work similar to autosomal genes and defects here can cause issues such as short stature, schizophrenia, and bipolar disorder (21-23). PAR1 also serves as a region to allow for pairing with the $\mathrm{X}$ chromosome that is crucial for meiosis (24).

The MSY is a far larger region of the $\mathrm{Y}$ chromosome and is unique in that it does not recombine with its $X$ chromosome pair. There are three classes of sequences within the MSY region; X-transposed, X-degenerate, and amplionic (25). The majority of the genes involved in male reproduction and spermatogenesis are located in the amplionic regions $(19,26)$. The amplionic regions are comprised of 9 separate protein-coding multi-copy gene families that total 10.2 Mb pairs. These amplionic sequences demonstrate sequence pairs that are nearly identical with other regions within the MSY. Eight of these nine regions exist as palindromic sequences, consisting of highly similar inverted sequence repeats with short spacer sequence dividers. The ninth sequence, called TSPY, exists as a tandem array of repeats located on the $\mathrm{Yp}$ arm. It is suggested these palindromic sequences exist to allow for intra-chromosomal gene transfer to preserve genes important for male fertility and prevent the accumulation of mutations that would eventually lead to the reduction of fertility. However, this also allows for deletions and or duplications of repeated sequences through non-allelic homologous recombination which can negatively impact male fertility $(9,25,27-29)$. It is this mechanism that can lead to gene copy number variations with resultant difficulties conceiving. Interestingly, even among healthy men there are variations in the $\mathrm{Y}$ amplionic gene copy number (30-32). Some of this variation is related to $\mathrm{Y}$ haplogroups, ethnicity, and geographic region, further complicating study of this phenomenon (32). This review will focus on $\mathrm{CNV}$ on the $\mathrm{Y}$ chromosome and how they play a role in male infertility and overall health.

\section{Initial study of copy number variation on the $Y$ chromosome}

Infertility-related copy number variations were first recognized as a clinical entity in 1976 by Tiepolo and Zuffardi (33). In their study of 1170 sub-fertile men, karyotype analyses revealed a subset of men with a deletion within the Yq11 region. These men had normal body habitus in contrast to the previously recognized Klinefelter's syndrome, the predominant cause of genetic male infertility (34-36). The deleted regions were termed 'azoospermia factor' (AZF). The AZF region was further confirmed by both cytogenetic and molecular studies (37-39). Building on this work, Vogt et al. sought to further define this region and determine if it were a single gene locus or multiple loci by screening 376 men with normal karyotype and azoospermia or severe oligospermia. The Y chromosome was specifically analyzed for 76 different DNA loci. Through this technique they were able to define 3 distinct regions within Yq, termed $\mathrm{AZFa}, \mathrm{AZFb}$, and AZFc (40). This was the first clinical work to demonstrate how copy number variation, in this case reduced copy number, could lead to fertility issues in men.

Clinically, it has been suggested that copy number variations can be defined in 3 ways: (I) AZF deletions (and partial $\mathrm{AZFa}$ and $\mathrm{AZFb}$ ), (II) partial AZFc deletions/ duplications, (III) the TSPY region (9). AZFc is the largest region measuring at $4.2 \mathrm{Mb}$ followed by $\mathrm{AZFb}$ at $3.2 \mathrm{Mb}$ and finally AZFa at $792 \mathrm{~Kb}$. The palindromic sequence within AZFc is the largest, most uniform, and elaborate of identified inverted repeats among previously studied organisms and is about three times longer than the next largest palindrome in humans (located on chromosome 5). It measures $3 \mathrm{Mb}$ in length (41). This has led to great interest and further study, however studying large palindromic 
sequences makes the endeavor more complicated due to the difficulty in ordering the defined sequences since they appear similar (41). Some of this complex work is detailed in Kuroda-Kawaguchi et al. (41).

\section{AZFa}

The AZFa region is the shortest of the three named regions, measuring in at $792 \mathrm{~Kb}(42)$. It contains only four coding genes that are ubiquitously expressed within the body but that each have only a single copy within the AZFa region (20). This region is found deleted about $0.5-4 \%$ of the time when AZF deletions are found (43). Despite being the smallest of the AZF regions, complete deletion leads to the most severe phenotype, Sertoli-cell only. The 4 genes isolated to this region are USP9Y, DBY, UTY, and TBY4 (26,44-46). Both USP9Y and $D B Y$ play important roles in spermatogenesis with it being believed that $D B Y$ is the more important of the two genes. At this time, UTY and TBY4 have unclear roles (20). No men with an identified AZFa deletion have ever been found to have sperm. Since these are only single gene copies, any copy number variation in this region has extreme consequences.

\section{AZFb}

The $\mathrm{AZFb}$ region is in the midportion of $\mathrm{Yq} 11$ and spans a total of $3.2 \mathrm{Mb}$, with $1.5 \mathrm{Mb}$ overlapping with the AZFc region. It is found deleted in approximately $1-3 \%$ of cases with AZF deletions (43). It contains 3 single copy regions, a 19-satellite repeat array, and 14 multi-copy amplicons organized into 6 sequence families. AZFb contains 15 coding protein genes and 17 non coding RNAs (20). The classical copy number variation within this section is a complete deletion that overlaps $1.5 \mathrm{Mb}$ with AZFc and leads to a complete loss of 32 coding genes. It is generally accepted that AZFb deletions lead to azoospermia, though with elements of maturation arrest as opposed to Sertolicell only found in AZFa. However, there have been rare reports of men with $\mathrm{AZFb}$ deletions that had some residual sperm production, likely due to an aberrant deletion patterns $(47,48)$. Another article within this journal will go into more depth with regards to AZFb.

\section{AZFc}

AZFc is the largest of the coding regions and most complex. It measures at $4.2 \mathrm{Mb}$ total and complete deletions are found in $80 \%$ of all AZF deletions (43). AZFc is arranged in 3 large palindromes that are each comprised of six distinct amplicons. The amplicons range in size from 115 to 678 $\mathrm{kb}$ each (41). A complete AZFc deletion, also known as a b2/b4 deletion based upon amplicon break points, is most commonly seen and tends to exhibit the least severe phenotype of the AZF deletions being the only one where patients could have either oligospermia or azoospermia but with a $50 \%$ chance of retrieving sperm on testicular extraction (49). The full AZFc deletion will be discussed in another article in this edition. This article will focus on specific partial deletions and copy number variations within AZFc.

When AZFc was first being studied it was proposed that in addition to the entire region being deleted, there were sub-sections of the region that would be susceptible to deletion given their structure (50). These specific deletions were identified and characterized as gr/gr deletion $(1.6 \mathrm{Mb})$ and the b1/b3 deletion (1.6 Mb) (51). The gr/gr deletion was of concern because it removes 9 of the 32 gene coding units within AZFc and occurs within a region that is needed for normal spermatogenesis. However, for 8 of these 9 gene families, the deletions only reduce the copy number of these genes since gene copies are located elsewhere on the $\mathrm{Y}$ chromosome. The initial study defining these alternate deletion patterns included 689 men, of whom 473 had spermatogenic failure, and found 22 men with a $\mathrm{gr} / \mathrm{gr}$ deletion and one man who had a b1/b3 deletion. The names were determined by genetic break points. After controlling for $\mathrm{Y}$ haplogroups, the group found that men with a gr/gr deletion had a significantly increased risk of spermatogenic failure (51). This group went on to identify another deletion within the AZFc region that affected gene copy numbers and referred to as the b2/b3 deletion based upon amplionic break points (52).

The major genes that have their copy number significantly affected by these deletions are the $D A Z$ and $C D Y 1$ genes. These genes, and their reduction in copy number, have been known to have a significant impact on spermatogenesis since the 1990s (52-54). While these early studies focused on DAZ1 and DAZ2 further studies went on to examine deletions of other members of the $D A Z$ family and still found effects on spermatogenesis related to $D A Z$ copy number $(55,56)$. Copy number of these genes playing an important role was further suggested by German group that compared 170 men with normal spermatogenesis to 348 men with impaired spermatogenesis. The gr/gr deletion was found in 14 men with impaired spermatogenesis and 
in 3 men with normal spermatogenesis, and two of them had fathered children. The b1/b3 deletion was found in 1 normal and 1 impaired man and the b2/b3 deletion was found in 5 normal men and only 2 of the abnormal spermatogenesis group. And while the gr/gr deletion was more common in the impaired group, it was not a significant difference, and therefore this group suggested that while these particular copy number variations can play a role in spermatogenesis, these deletions and the changes in copy number may not tell the entire store (57).

Another group out of India examined 822 infertile men and 225 men with proven fertility. They found gr/gr deletions in 48 of the infertile men and 2 of the fertile men, they found b1/b3 deletions in 1 infertile man and 0 fertile men, and in the $\mathrm{b} 2 / \mathrm{b} 3$ group they found 2 and 1 deletions respectively within the infertile and fertile groups. And while the $\mathrm{gr} / \mathrm{gr}$ deletion group did have a significantly increased risk of infertility, their sperm concentrations, while trending lower, were not significantly different (54.20 \pm 57.45 vs. $72.49 \pm 60.06$ million/mL) (58).

Other studies continued to examine these different deletions and their effects on spermatogenesis, with studies often deciding to limit to certain populations to better control for $\mathrm{Y}$ haplogroups. A meta-analysis of the gr/gr deletion incorporated 18 case-control studies with a total of 6,388 cases and 6,011 controls and found that $6.9 \%$ of cases had the gr/gr deletion while $4.7 \%$ of controls also had the deletion. While there was a significantly increased risk of infertility in the cases group, these alterations in copy number clearly cannot tell the entire story. There was also a correlation of gr/gr deletion based upon Y haplogroups and geographic region. This studied stated that at this time they would not recommend routine screening for the $\mathrm{gr} / \mathrm{gr}$ mutation as it may lead to more questions than answers (59). While some of the early studies looking at b2/b3 deletions did not demonstrate significant effects, a meta-analysis that incorporated 24 studies and had 8,892 oligo/azoospermic men compared to 5,842 normozoospermic men was performed to better examine the data. The b2/b3 deletion was found in 241 oligo/azoospermic men $(2.7 \%)$ and 118 normozoospermic men $(2 \%)$. In the meta-analysis, the fixed model demonstrated an OR of 1.3 that having the b2/b3 deletion would have a significant negative impact on spermatogenesis. Much like the analysis looking at gr/gr, these findings tied heavily to different haplogroups and geographic regions.

\section{TSPY1 gene array}

The testis-specific protein $\mathrm{Y}$ encoded 1 (TSPY1) gene array is located on the Yp arm. The TSPY1 gene copies exist as $20.4 \mathrm{~kb}$ sequences that occur in tandem repeats. These repeated sequences range in number from 11-76 and are highly variable across haplogroups $(60,61)$. It is suspected that copy numbers outside this range are incompatible with life and thus are not found in current populations (62). Given this belief and the large copy number variability of the TSPY1 gene it has been examined for relation to sperm counts and fertility. A 2006 study from the Czech Republic noted copy numbers varying from 30-60 and that increased number of copies of TSPY1 led to a significant increase in infertility (63). In direct contradiction to this finding was a study in 2009 of Italian men, where copy numbers ranged from 21-35, and found that having fewer copies of TSPY1 led to a significant decrease in sperm counts and fertility (64). However, there was a third study examining TSPY1 copy number in 2010 performed on Dutch men that found no effect on TSPY1 copy number and fertility when comparing fertile and infertile men. In this study, the control group had a median TSPY1 copy number of 34 (26-76 copies) while the infertile group had a median TSPY1 copy number of 35 (20-73 copies) (65). Three studies, three different results. The group that produced the Italian study has theorized subsequently that because of the variation across the populations, controlling for $\mathrm{Y}$ haplogroups during these studies is important. This group expanded on their initial study, increasing their study size to 212 men having abnormal semen parameters compared to 168 men with normal semen parameters and continued to find a significantly lower TSPY1 copy number in the infertile group $(28.5 \pm 7.9$ vs. $32.6 \pm 10.1$ copies) (66). A very thorough study out of China in 2013 examined 2,272 Han Chinese men and found seven distinct $\mathrm{Y}$ haplogroups. These haplogroups had significantly different mean number of copies of the TSPY1 gene. Overall the study found that men with $<21$ copies of TSPY1 and men with $>55$ copies of TSPY1 had a significantly lower sperm production and increased chanced of spermatogenic failure compared to men with 21-35 copies of the gene (67). The TSPY1 gene thus far appears to be the clearest example of $\mathrm{CNV}$ having significant, and variable, impact on spermatogenesis.

\section{Other genes and sequences}

There have been several other genes or sequences studied in 
relation to copy number variation on the $Y$ chromosome and fertility. The DYZ1 array comprises between $20-40 \%$ of the $\mathrm{Y}$ chromosome and was found to contain a pentameric repeat with about 3,000-4,300 copies of the gene array on the $Y$ chromosome (68-71). Initially the DYZ1 array was thought to be of little importance because it does not participate in recombination but later studies revealed it could help with chromatin stabilization $(72,73)$. These DYZ1 arrays are interspersed through the previously mentioned AZFa, b, c regions. This led to a group in India examining the DYZ1 array for copy number variation and comparing 67 infertile men to 31 men with a normal semen analysis. They found a reduced DYZ1 copy number had significantly increased risk of infertility (74). Interestingly, even in monozygotic twins there has been found to be copy number variation of DYZ1 on the $\mathrm{Y}$ chromosome, opening further questions into the effects of copy number variation as a whole (75).

Another gene with noted copy number variation linked to fertility and spermatogenesis has been $R B M Y 1$. It is known in $\mathrm{AZFb}$ deletions, all active copies of RBMY1 are deleted, which leads to azoospermia (76). It has also been observed that there is significant copy number variation of the RBMY1 gene in the general population and the full implications of this are not fully understood (77). A study of Han Chinese men to compared RBMY1 copy number between 506 men with normozoospermia and 564 men with oligo or athenozoospermia without previously identified chromosomal deletion to examine for copy number and relation to sperm motility. The study found that men with fewer than 6 copies of RBMY1 were at an increased risk of athenozoospermia. Six copies of the gene were found to be the average number within this population. In contrast, 376 Estonian men with oligo or azoospermia without known prior chromosomal deletions were analyzed for RBMY1 copy number and its effects on sperm motility. Unlike the Chinese study, there was no evidence of RBMY1 gene copy number playing a role in determining sperm motility (78).

\section{Y chromosome copy number variation-beyond infertility}

While fertility consequences remain the largest concern for $\mathrm{CNV}$ of the $\mathrm{Y}$ chromosome, recent studies have demonstrated there could be health issues beyond male factor infertility. Once genes were identified on the $\mathrm{Y}$ chromosome, groups began to look for this gene expression in other tissues of the body. Interestingly the genes most commonly found in other tissues of the body were usually within the $\mathrm{AZFa}$ and $\mathrm{AZFb}$ regions with relatively few in the AZFc region, despite it being the largest (79). Colaco and Modi then examined the putative functions of these genes and as expected most of the functions were related to spermatogenesis, but they also found $14 \%$ of genes involved in regulation of gene expression, chromatin organization, and regulation of protein synthesis. In addition, 24\% of the genes code for products involved in protein-protein interactions, $18 \%$ in nucleic acid binding, and $12 \%$ in RNA binding (80). With the wide expression of these genes throughout the body and the alternative functions besides spermatogenesis, it can be understood how these genes may play a role in other health issues.

Given the importance of the Y chromosome to testicular function; it has long been suspected that genes on the $\mathrm{Y}$ chromosome can play a role in testicular cancer development. This has been seen in the development of gonadoblastoma in Turner's syndrome patients (81) as well in other germ cell tumors in patients with disorders of sexual development (82). The previously discussed $\mathrm{gr} / \mathrm{gr}$ deletion has been implicated in the development of testicular germ cell tumors $(83,84)$. Beyond the testicle, loss of the $\mathrm{Y}$ chromosome in peripheral blood has been found to be a risk factor for the development of colorectal and prostate cancer (85). Additionally, certain deletions of genes from the $\mathrm{Y}$ chromosome can lead to more aggressive types of prostate cancer (86-88). Interestingly, the RBMY1 gene previously discussed is only expressed within the testicle, but changes in copy number have been implicated as a risk factor for hepatocellular carcinoma in men (89) and could also contribute to a poorer prognosis in men with hepatocellular carcinoma (90).

In addition to cancer risks associated with changes in $\mathrm{Y}$ chromosome gene copy numbers, these genes can play a role in neuropsychiatric disorders. Three of the AZFa genes and four of the $\mathrm{AZFb}$ genes are expressed in the cerebral cortex (80). There is evidence that changes to these genes copy numbers can be risk factors for ischemic stroke (91) and the development of Parkinson's disease (92). Colaco and Modi were able to utilize the Decipher database, which collects clinical data on patients with CNVs, to identify 84 men with copy number variations within the AZF regions. There was clinical information in the database on 71 of these men, with 21 of these men with AZF CNVs also having neuropsychiatric concerns. Examples included delayed development, intellectual disorders, and anxiety or mood disorders (80). There is even evidence in mice that $\mathrm{Y}$ chromosome $\mathrm{CNV}$ can be linked to central nervous system 
autoimmune diseases in female offspring (93).

Other studies suggest, at least in a European population, certain $\mathrm{Y}$ haplogroups can play a role in the risk of developing cardiovascular disease (94). Another study noted that changes in UTY expression, previously as mentioned as being within the AZFa region, could affect cardiovascular risk by playing a late role in development of atherosclerosis (95). Some of these $\mathrm{Y}$ chromosome effects are beyond the scope of this review as they do not strictly deal with $\mathrm{CNV}$, but Maan et al. have an excellent review of the topic (96).

\section{Conclusions}

The $\mathrm{Y}$ chromosome is unique among human chromosomes in both its small size and uniquely repetitive structure. It is this unusual structure that not only provides protection from genomic degradation over time but can also lead to changes in gene copy number expression that can have dramatic effects on both fertility and in some cases overall health. While the effects of AZF whole deletions appear to be fairly well understood, specific gene copy number variations and their effects are still being isolated and understood within the context of fertility and general health. The study of this phenomenon is further complicated because it appears that $\mathrm{Y}$ haplogroups can play a significant role in how much copy number variation affects overall fertility. This can make comparing data and studies across populations more complicated. As it stands now, given the limited knowledge, testing specifically for these CNVs likely will not have an impact on clinical care for a man with male factor infertility. For CNV testing to play a critical role in male infertility evaluation, further research needs to be completed to look more in depth at specific areas for $\mathrm{CNV}$ on the $\mathrm{Y}$ chromosome and better defining the number of $\mathrm{CNV}$ that become are clinically important. Additionally, utilization in male factor evaluation would require clinically accurate and accessible testing as opposed to research testing. As research and understanding of the topic continues to grow, CNVs will likely become more frequently tested to allow for improved clinical care in the future.

\section{Acknowledgments}

Funding: None.

\section{Footnote}

Provenance and Peer Review: This article was commissioned by the Guest Editors (Keith Jarvi and Jared Bieniek) for the series "Genetic Causes and Management of Male Infertility" published in Translational Andrology and Urology. The article was sent for external peer review organized by the Guest Editors and the editorial office.

Conflicts of Interest: The author has completed the ICMJE uniform disclosure form (available at http://dx.doi. org/10.21037/tau.2020.04.06). The series "Genetic Causes and Management of Male Infertility" was commissioned by the editorial office without any funding or sponsorship. The author has no other conflicts of interest to declare.

Ethical Statement: The author is accountable for all aspects of the work in ensuring that questions related to the accuracy or integrity of any part of the work are appropriately investigated and resolved.

Open Access Statement: This is an Open Access article distributed in accordance with the Creative Commons Attribution-NonCommercial-NoDerivs 4.0 International License (CC BY-NC-ND 4.0), which permits the noncommercial replication and distribution of the article with the strict proviso that no changes or edits are made and the original work is properly cited (including links to both the formal publication through the relevant DOI and the license). See: https://creativecommons.org/licenses/by-nc-nd/4.0/.

\section{References}

1. Male Infertility Best Practice Policy Committee of the American Urological Association., Practice Committee of the American Society for Reproductive Medicine. Report on optimal evaluation of the infertile male. Fertil Steril 2006;86:S202-9.

2. Thonneau P, Marchand S, Tallec A, et al. Incidence and main causes of infertility in a resident population $(1,850,000)$ of three French regions (1988-1989). Hum Reprod 1991;6:811-6.

3. Honig SC, Lipshultz LI, Jarow J. Significant medical pathology uncovered by a comprehensive male infertility evaluation. Fertil Steril 1994;62:1028-34.

4. Anderson JE, Farr SL, Jamieson DJ, et al. Infertility services reported by men in the United States: national survey data. Fertil Steril 2009;91:2466-70.

5. Jarow J, Sigman M, Kolettis PN, et al. The Optimal Evaluation of the Infertile Male: AUA Best Practice Statement. American Urologic Association. 2011. 
6. Wosnitzer MS. Genetic evaluation of male infertility. Transl Androl Urol 2014;3:17-26.

7. Chandley AC. Chromosome anomalies and Y chromosome microdeletions as causal factors in male infertility. Hum Reprod 1998;13 Suppl 1:45-50.

8. Van Assche E, Bonduelle $M$, Tournaye H, et al. Cytogenetics of infertile men. Hum Reprod 1996;11 Suppl 4:1-24; discussion 25-6.

9. Krausz C, Casamonti E. Spermatogenic failure and the $Y$ chromosome. Hum Genet 2017;136:637-55.

10. Foresta C, Moro E, Garolla A, et al. Y chromosome microdeletions in cryptorchidism and idiopathic infertility. J Clin Endocrinol Metab 1999;84:3660-5.

11. Simoni M, Tüttelmann F, Gromoll J, et al. Clinical consequences of microdeletions of the $\mathrm{Y}$ chromosome: the extended Münster experience. Reprod Biomed Online 2008;16:289-303.

12. Lupski JR. Cognitive phenotypes and genomic copy number variations. JAMA 2015;313:2029-30.

13. Shi W, Massaia A, Louzada S, et al. Copy number variation arising from gene conversion on the human $\mathrm{Y}$ chromosome. Hum Genet 2018;137:73-83.

14. Hastings PJ, Lupski JR, Rosenberg SM, et al. Mechanisms of change in gene copy number. Nat Rev Genet 2009;10:551-64.

15. Männik K, Mägi R, Macé A, et al. Copy number variations and cognitive phenotypes in unselected populations. JAMA 2015;313:2044-54.

16. Mullen SA, Carvill GL, Bellows S, et al. Copy number variants are frequent in genetic generalized epilepsy with intellectual disability. Neurology 2013;81:1507-14.

17. Liang L, Fang JY, Xu J. Gastric cancer and gene copy number variation: emerging cancer drivers for targeted therapy. Oncogene 2016;35:1475-82.

18. Lau YFC, Li Y, Kido T. Gonadoblastoma locus and the TSPY gene on the human Y chromosome. Birth Defects Res C Embryo Today 2009;87:114-22.

19. Navarro-Costa P. Sex, rebellion and decadence: the scandalous evolutionary history of the human $\mathrm{Y}$ chromosome. Biochim Biophys Acta 2012;1822:1851-63.

20. Colaco S, Modi D. Genetics of the human Y chromosome and its association with male infertility. Reprod Biol Endocrinol 2018;16:14.

21. Flaquer A, Jamra RA, Etterer K, et al. A new susceptibility locus for bipolar affective disorder in PAR1 on Xp22.3/ Yp11.3. Am J Med Genet B Neuropsychiatr Genet 2010;153B:1110-4.

22. Rao E, Weiss B, Fukami M, et al. Pseudoautosomal deletions encompassing a novel homeobox gene cause growth failure in idiopathic short stature and Turner syndrome. Nat Genet 1997;16:54-63.

23. Lencz T, Morgan TV, Athanasiou M, et al. Converging evidence for a pseudoautosomal cytokine receptor gene locus in schizophrenia. Mol Psychiatry 2007;12:572-80.

24. Kauppi L, Barchi M, Baudat F, et al. Distinct properties of the $\mathrm{XY}$ pseudoautosomal region crucial for male meiosis. Science 2011;331:916-20.

25. Skaletsky H, Kuroda-kawaguchi T, Minx PJ, et al. The male-specific region of the human $\mathrm{Y}$ chromosome is a mosaic of discrete sequence classes. Nature 2003;423:82537.

26. Lahn BT, Page DC. Functional coherence of the human $Y$ chromosome. Science 1997;278:675-80.

27. Vegesna R, Tomaszkiewicz M, Medvedev P, et al. Dosage regulation, and variation in gene expression and copy number of human $Y$ chromosome ampliconic genes. PLOS Genet 2019;15:e1008369.

28. Rozen S, Skaletsky H, Marszalek JD, et al. Abundant gene conversion between arms of palindromes in human and ape Y chromosomes. Nature 2003;423:873-6.

29. Lemos B, Branco AT, Hartl DL. Epigenetic effects of polymorphic $\mathrm{Y}$ chromosomes modulate chromatin components, immune response, and sexual conflict. Proc Natl Acad Sci U S A 2010;107:15826-31.

30. Skov L, Schierup MH. Analysis of 62 hybrid assembled human $\mathrm{Y}$ chromosomes exposes rapid structural changes and high rates of gene conversion. PLoS Genet 2017;13:e1006834.

31. Lucotte EA, Skov L, Jensen JM, et al. Dynamic Copy Number Evolution of X- and Y-Linked Ampliconic Genes in Human Populations. Genetics 2018;209:907-20.

32. Ye D, Zaidi AA, Tomaszkiewicz M, et al. High Levels of Copy Number Variation of Ampliconic Genes across Major Human Y Haplogroups. Genome Biol Evol 2018;10:1333-50.

33. Tiepolo L, Zuffardi O. Localization of factors controlling spermatogenesis in the nonfluorescent portion of the human Y chromosome long arm. Hum Genet 1976;34:119-24.

34. Klinefelter H, Reifenstein E, Albright F. Syndrome Characterized by Gynecomastia, Aspermatogenesis without A-Leydigism, and Increased Excretion of Follicle Stimulating Hormone. J Clin Endocrinol Metab 1942;2:615-27.

35. Jacobs PA, Strong JA. A Case of Human Intersexuality Having a Possible XXY Sex-Determining Mechanism. 
Nature 1959;183:302-3.

36. Lanfranco F, Kamischke A, Zitzmann M, et al. Klinefelter' s syndrome. Lancet 2004;364:273-83.

37. Vergnaud G, Page DC, Simmler MC, et al. A deletion map of the human $\mathrm{Y}$ chromosome based on DNA hybridization. Am J Hum Genet 1986;38:109-24.

38. Ferguson-Smith MA, Affara NA, Magenis RE. Ordering of Y-specific sequences by deletion mapping and analysis of $\mathrm{X}-\mathrm{Y}$ interchange males and females. Development 1987;101 Suppl:41-50.

39. Andersson M, Page DC, Pettay D, et al. Y;autosome translocations and mosaicism in the aetiology of $45, \mathrm{X}$ maleness: assignment of fertility factor to distal Yq11. Hum Genet 1988;79:2-7.

40. Vogt PH, Edelmann A, Kirsch S, et al. Human Y chromosome azoospermia factors (AZF) mapped to different subregions in Yq11. Hum Mol Genet 1996;5:933-43.

41. Kuroda-Kawaguchi T, Skaletsky H, Brown LG, et al. The AZFc region of the $\mathrm{Y}$ chromosome features massive palindromes and uniform recurrent deletions in infertile men. Nat Genet 2001;29:279-86.

42. Kamp C, Hirschmann P, Voss H, et al. Two long homologous retroviral sequence blocks in proximal Yq11 cause AZFa microdeletions as a result of intrachromosomal recombination events. Hum Mol Genet 2000;9:2563-72.

43. Krausz C, Hoefsloot L, Simoni M, et al. EAA/EMQN best practice guidelines for molecular diagnosis of Y-chromosomal microdeletions: state-of-the-art 2013. Andrology 2014;2:5-19.

44. Luddi A, Margollicci M, Gambera L, et al. Spermatogenesis in a man with complete deletion of USP9Y. N Engl J Med 2009;360:881-5.

45. Laaser I, Theis FJ, de Angelis MH, et al. Huge splicing frequency in human Y chromosomal UTY gene. OMICS 2011;15:141-54

46. Yang $X$, Leng $X$, Tu $W$, et al. Spermatogenic phenotype of testis-specific protein, Y-encoded, 1 (TSPY1) dosage deficiency is independent of variations in TSPY-like 1 (TSPYL1) and TSPY-like 5 (TSPYL5): a case-control study in a Han Chinese population. Reprod Fertil Dev 2018;30:555-62.

47. Stouffs K, Vloeberghs V, Gheldof A, et al. Are AZFb deletions always incompatible with sperm production? Andrology 2017;5:691-4.

48. Kleiman SE, Yogev L, Lehavi O, et al. The likelihood of finding mature sperm cells in men with $\mathrm{AZFb}$ or $\mathrm{AZFb}-\mathrm{c}$ deletions: six new cases and a review of the literature (1994-2010). Fertil Steril 2011;95:2005-12, 2012.e1-4.
49. Hopps CV, Mielnik A, Goldstein M, et al. Detection of sperm in men with $\mathrm{Y}$ chromosome microdeletions of the AZFa, $\mathrm{AZFb}$ and AZFc regions. Hum Reprod 2003;18:1660-5.

50. Yen P. The fragility of fertility. Nat Genet 2001;29:243-4.

51. Repping S, Skaletsky H, Brown L, et al. Polymorphism for a 1.6-Mb deletion of the human $\mathrm{Y}$ chromosome persists through balance between recurrent mutation and haploid selection. Nat Genet 2003;35:247-51.

52. Repping S, van Daalen SKM, Korver CM, et al. A family of human $\mathrm{Y}$ chromosomes has dispersed throughout northern Eurasia despite a 1.8-Mb deletion in the azoospermia factor c region. Genomics 2004;83:1046-52.

53. Habermann B, Mi HF, Edelmann A, et al. DAZ (Deleted in AZoospermia) genes encode proteins located in human late spermatids and in sperm tails. Hum Reprod 1998;13:363-9.

54. Lahn BT, Tang ZL, Zhou J, et al. Previously uncharacterized histone acetyltransferases implicated in mammalian spermatogenesis. Proc Natl Acad Sci U S A 2002;99:8707-12.

55. Fernandes S, Paracchini S, Meyer LH, et al. A large AZFc deletion removes DAZ3/DAZ4 and nearby genes from men in Y haplogroup N. Am J Hum Genet 2004;74:180-7.

56. Fernandes AT, Fernandes $S$, Goncalves R, et al. DAZ gene copies: evidence of $Y$ chromosome evolution. Mol Hum Reprod 2006;12:519-23.

57. Hucklenbroich K, Gromoll J, Heinrich M, et al. Partial deletions in the AZFc region of the $\mathrm{Y}$ chromosome occur in men with impaired as well as normal spermatogenesis. Hum Reprod 2005;20:191-7.

58. Bansal SK, Jaiswal D, Gupta N, et al. Gr/gr deletions on Y-chromosome correlate with male infertility: an original study, meta-analyses, and trial sequential analyses. Sci Rep 2016;6:19798.

59. Stouffs K, Lissens W, Tournaye H, Haentjens P. What about $\mathrm{gr} / \mathrm{gr}$ deletions and male infertility? Systematic review and meta-analysis. Hum Reprod Update 2011;17:197-209.

60. Tyler-Smith C, Taylor L, Muller U. Structure of a hypervariable tandemly repeated DNA sequence on the short arm of the human $\mathrm{Y}$ chromosome. J Mol Biol 1988;203:837-48.

61. Mathias N, Bayes M, Tyler-Smith C. Highly informative compound haplotypes for the human $\mathrm{Y}$ chromosome. Hum Mol Genet 1994;3:115-23.

62. Tyler-Smith C. An evolutionary perspective on Y-chromosomal variation and male infertility. Int J Androl 
2008;31:376-82.

63. Vodicka R, Vrtel R, Dusek L, et al. TSPY gene copy number as a potential new risk factor for male infertility. Reprod Biomed Online 2007;14:579-87.

64. Giachini C, Nuti F, Turner DJ, et al. TSPY1 copy number variation influences spermatogenesis and shows differences among Y lineages. J Clin Endocrinol Metab 2009;94:401622.

65. Nickkholgh B, Noordam MJ, Hovingh SE, et al. Y chromosome TSPY copy numbers and semen quality. Fertil Steril 2010;94:1744-7.

66. Krausz C, Chianese C, Giachini C, et al. The Y chromosome-linked copy number variations and male fertility. J Endocrinol Invest 2011;34:376-82.

67. Shen Y, Yan Y, Liu Y, et al. A significant effect of the TSPY1 copy number on spermatogenesis efficiency and the phenotypic expression of the gr/gr deletion. Hum Mol Genet 2013;22:1679-95.

68. Ali S, Hasnain SE. Genomics of the human Y-chromosome. 1. Association with male infertility. Gene 2003;321:25-37.

69. Yadav SK, Kumari A, Ali S. Fate of the human Y chromosome linked genes and loci in prostate cancer cell lines DU145 and LNCaP. BMC Genomics 2013;14:323.

70. Cooke H. Repeated sequence specific to human males. Nature 1976;262:182-6.

71. Nakahori Y, Mitani K, Yamada M, et al. A human Y-chromosome specific repeated DNA family (DYZ1) consists of a tandem array of pentanucleotides. Nucleic Acids Res 1986;14:7569-80.

72. Lahn BT, Pearson NM, Jegalian K. The human Y chromosome, in the light of evolution. Nat Rev Genet 2001;2:207-16.

73. Pathak D, Premi S, Srivastava J, et al. Genomic instability of the DYZ1 repeat in patients with Y chromosome anomalies and males exposed to natural background radiation. DNA Res 2006;13:103-9.

74. Kumari A, Yadav SK, Ali S. Organizational and functional status of the Y-linked genes and loci in the infertile patients having normal spermiogram. PLoS One 2012;7:e41488.

75. Yadav SK, Kumari A, Javed S, Ali S. DYZ1 arrays show sequence variation between the monozygotic males. BMC Genet 2014;15:19.

76. Repping S, Skaletsky H, Lange J, et al. Recombination between palindromes $\mathrm{P} 5$ and $\mathrm{P} 1$ on the human $\mathrm{Y}$ chromosome causes massive deletions and spermatogenic failure. Am J Hum Genet 2002;71:906-22.

77. Wei W, Fitzgerald TW, Ayub Q, et al. Copy number variation in the human $\mathrm{Y}$ chromosome in the UK population. Hum Genet 2015;134:789-800.

78. Shi W, Louzada S, Grigorova M, et al. Evolutionary and functional analysis of RBMY1 gene copy number variation on the human $\mathrm{Y}$ chromosome. Hum Mol Genet 2019;28:2785-98.

79. Uhlén M, Fagerberg L, Hallström BM, et al. Proteomics. Tissue-based map of the human proteome. Science 2015;347:1260419.

80. Colaco S, Modi D. Consequences of Y chromosome microdeletions beyond male infertility. J Assist Reprod Genet 2019;36:1329-37.

81. Gravholt CH, Fedder J, Naeraa RW, et al. Occurrence of gonadoblastoma in females with Turner syndrome and Y chromosome material: a population study. J Clin Endocrinol Metab 2000;85:3199-202.

82. Jørgensen A, Lindhardt Johansen M, et al. Pathogenesis of germ cell neoplasia in testicular dysgenesis and disorders of sex development. Semin Cell Dev Biol 2015;45:124-37.

83. Nathanson KL, Kanetsky PA, Hawes R, et al. The Y deletion gr/gr and susceptibility to testicular germ cell tumor. Am J Hum Genet 2005;77:1034-43.

84. Moreno-Mendoza D, Casamonti E, Paoli D, et al. gr/ gr deletion predisposes to testicular germ cell tumour independently from altered spermatogenesis: results from the largest European study. Eur J Hum Genet 2019;27:1578-88.

85. Noveski P, Madjunkova S, Sukarova Stefanovska E, et al. Loss of Y Chromosome in Peripheral Blood of Colorectal and Prostate Cancer Patients. PLoS One 2016;11:e0146264.

86. Li N, Dhar SS, Chen T-Y, et al. JARID1D Is a Suppressor and Prognostic Marker of Prostate Cancer Invasion and Metastasis. Cancer Res 2016;76:831-43.

87. Zhu Y, Ren S, Jing T, et al. Clinical utility of a novel urinebased gene fusion TTTY15-USP9Y in predicting prostate biopsy outcome. Urol Oncol 2015;33:384.e9-20.

88. Komura K, Yoshikawa Y, Shimamura T, et al. ATR inhibition controls aggressive prostate tumors deficient in Y-linked histone demethylase KDM5D. J Clin Invest 2018;128:2979-95.

89. Tsuei DJ, Lee PH, Peng HY, et al. Male germ cellspecific RNA binding protein RBMY: a new oncogene explaining male predominance in liver cancer. PLoS One 2011;6:e26948.

90. Chua HH, Tsuei DJ, Lee PH, et al. RBMY, a novel inhibitor of glycogen synthase kinase 3 beta, increases tumor stemness and predicts poor prognosis of hepatocellular carcinoma. Hepatology 2015;62:1480-96. 
91. Tian Y, Stamova B, Jickling GC, et al. Y chromosome gene expression in the blood of male patients with ischemic stroke compared with male controls. Gend Med 2012;9:68-75.e3.

92. Sun AG, Wang J, Shan YZ, et al. Identifying distinct candidate genes for early Parkinson's disease by analysis of gene expression in whole blood. Neuro Endocrinol Lett 2014;35:398-404.

93. Case LK, Wall EH, Osmanski EE, et al. Copy number variation in $\mathrm{Y}$ chromosome multicopy genes is linked to a paternal parent-of-origin effect on CNS autoimmune

Cite this article as: Rogers MJ. Y chromosome copy number variation and its effects on fertility and other health factors: a review. Transl Androl Urol 2021;10(3):1373-1382. doi: 10.21037/ tau.2020.04.06 disease in female offspring. Genome Biol 2015;16:28.

94. Charchar FJ, Bloomer LD, Barnes TA, et al. Inheritance of coronary artery disease in men: an analysis of the role of the Y chromosome. Lancet 2012;379:915-22.

95. Eales JM, Maan AA, Xu X, et al. Human Y Chromosome Exerts Pleiotropic Effects on Susceptibility to Atherosclerosis. Arterioscler Thromb Vasc Biol 2019;39:2386-401.

96. Maan AA, Eales J, Akbarov A, et al. The Y chromosome: a blueprint for men's health? Eur J Hum Genet 2017;25:1181-8. 